\title{
Joint Mexican position document on the treatment of atrial fibrillation
}

\author{
Posicionamiento conjunto acerca del tratamiento para fibrilación auricular
}

\begin{abstract}
Gerardo Rodríguez-Diez ${ }^{1 *}$, Manlio F. Márquez², Pedro Iturralde-Torres², Luis G. Molina-Fernández de L. , Gerardo Pozas-Garza ${ }^{4}$, Alejandro Cordero-Cabra ${ }^{5}$, and Ulises Rojel-Martínez ${ }^{6}$

${ }^{1}$ Arrhythmia and Cardiac Pacing Unit, Centro Médico Nacional Siglo XXI, Instituto de Seguridad Social y Servicios Sociales de los Trabajadores del Estado, Mexico City, ${ }^{2}$ Electrocardiology Service, Instituto Nacional de Cardiología Ignacio Chávez, Mexico City, ${ }^{3}$ Electrophysiology Unit, Hospital General de México, Mexico City, ${ }^{4}$ Instituto de Cardiología y Medicina Vascular, Hospital Zambrano Hellion TEC-Salud, Nuevo Léon; ${ }^{5}$ Servicio de Electrofisiología, Centro Médico Nacional de Occidente-Hospital de Especialidad, Instituto de Seguridad Social y Servicios Sociales de los Trabajadores del Estado (ISSSTE), Guadalajara; ${ }^{6}$ Arrhythmia and Cardiac Pacing Unit, Centro Médico Sur de los Servicios Médicos de Salud de Puebla, Puebla, Mexico
\end{abstract}

\begin{abstract}
Atrial fibrillation (AF) is a frequent arrhythmia; its prevalence is near $2 \%$ in the general population; in Mexico, more than onehalf million people are affected. AF needs to be considered as a public health problem. Because $A F$ is an independent risk factor associated with mortality, due to embolic events, heart failure, or sudden death; early diagnosis is of utmost importance. In unstable patients with a recent onset of $A F$, electrical cardioversion should be practiced. In stable patients, once thromboembolic measures have been taken, it is necessary to assess whether it is reasonable to administer an antiarrhythmic drug to restore sinus rhythm or performed electrical cardioversion. For recidivating cases of paroxysmal and persistent presentation, the most effective strategy is performed pulmonary vein isolation with either radiofrequency or cryoballoon energy. Permanent $A F$ is that in which recovery of sinus rhythm is not possible, the distinguishing feature of this phase is the uncontrollable variability of the ventricular frequency and could be treated pharmacologically with atrioventricular (AV) nodal blockers or with a VVIR pacemaker plus AV nodal ablation. The presence of AF has long been associated with the development of cerebral and systemic (pulmonary, limb, coronary, renal, and visceral) embolism. The prevention of embolisms in "valvular" AF should perform with Vitamin $K$ antagonists (VKA). For patients with AF not associated with mitral stenosis or a mechanical valve prosthesis, a choice can be made between anticoagulant drugs, VKA, or direct oral anticoagulants. Antiplatelet agents have the weakest effect in preventing embolism.
\end{abstract}

Key words: Atrial fibrillation. Drug treatment. Tromboprofilaxis. Cryoballoon ablation. Radiofrequency ablation.

\section{Resumen}

La fibrilación auricular ( $F A$ ) es una arritmia frecuente; su prevalencia es cercana al $2 \%$ en la población general, en México se ven afectados más de medio millón de personas por eso debe considerarse como un problema de salud pública. Debido a que la FA es un factor de riesgo independiente asociado a mortalidad, por eventos embólicos, insuficiencia cardíaca $o$

\footnotetext{
Correspondence:

*Gerardo Rodríguez-Diez

E-mail: dr.gerardord@gmail.com

Available online: $30-01-2020$

Date of acceptance: 31-10-2019

DOI: 10.24875/ACME.M20000096

Arch Cardiol Mex (Eng). 2020;90(1):69-76

www.archivoscardiologia.com

2604-7063 / @ 2019 Instituto Nacional de Cardiología Ignacio Chávez. Published by Permanyer. This is an open access article under the CC BY-NC-ND license (http://creativecommons.org/licenses/by-nc-nd/4.0/).
} 
muerte súbita, la identificación y diagnóstico temprano es de suma importancia. En el inicio reciente de FA en pacientes inestables, se debe practicar la cardioversión eléctrica. En pacientes estables, una vez que se han tomado medidas tromboembólicas, es necesario evaluar si es razonable administrar un medicamento antiarrítmico para restaurar el ritmo sinusal o realizar una cardioversión eléctrica. Para los casos que recidivan, ya sea paroxística o persistente, la estrategia más efectiva es realizar el aislamiento de la venas pulmonares con radiofrecuencia o crioablación con balón. La FA permanente es aquella en la que no es posible la recuperación del ritmo sinusal, la característica distintiva de esta fase de la FA es la variabilidad incontrolable de la frecuencia ventricular. Puede tratarse farmacológicamente con bloqueadores nodales AV o con un marcapasos VVIR mas ablación del nodo AV. La presencia de FA se ha asociado durante mucho tiempo con el desarrollo de embolia cerebral y sistémica (pulmonar, de extremidades, coronaria, renal y visceral). La prevención de embolias en la FA "valvular" debe realizarse con antagonistas de la vitamina K (AVK). Para los pacientes con FA no asociados con estenosis mitral o una prótesis valvular mecánica, se puede elegir entre medicamentos anticoagulantes, AVK o anticoagulantes orales directos (DOAC). Los agentes antiplaquetarios tienen el efecto más débil para prevenir la embolia.

Palabras clave: Fibrilación atrial. Tratamiento farmacológico. Tromboprofiláxis. Crioablación. Ablación con radiofrecuencia.

\section{What is known about the epidemiology of atrial fibrillation (AF) in Mexico? Can it be considered a public health problem?}

AF incidence and prevalence increase with age. Its prevalence is near to $2 \%$ in the general population, but it could be as high as $10 \%$ in those over 75 years $^{1,2}$. Before the Mexican Registry of AF (ReMeFA) was published a study market was conducted in Mexico in 2007, finding that, for a population of $105^{\prime} 338,982$ people the prevalence of cardiac arrhythmias was $2.4 \%$, with tachyarrhythmias being the most common with $56 \%$ (1'402,453 people), of which, AF was the most frequent arrhythmia, occupying $60.7 \%$ of tachycardia (or a total of 851,489 cases) $)^{3}$.

Today, we estimate that in Mexico, there are more than one and a half million people with $\mathrm{AF}$, with a prevalence ranging from $0.43 \%$ in the 40 to 49 age group to $8.48 \%$ in those over 80 years old, for an average of $1.58 \%$ in a population over 40 years of age ${ }^{3}$. Permanent or chronic AF represents $51.5 \%$ (corresponding to 438,134 , Mexicans). The ReMeFA 4 study was the first national multicenter registry, with clinical follow-up of 1 year, in 1201 subjects, on the comparison of AF treatment with a rhythm control strategy or with rate control. This study was carried out with the collaboration of 71 cardiologists and electrophysiologists. At 1 year follow-up, an incidence of $3 \%$ of ischemic cerebral vascular disease (CVD) was observed in the rate control strategy; significantly higher than $1 \%$ in the rhythm control strategy ( $p$ $=0.04)^{2}$. Worldwide, CVD is the second leading cause of death and the leading cause of disability ${ }^{1}$. CVD has become a health problem as a result of increased life expectancy and lifestyle changes, representing one of the leading causes of death in Mexico ${ }^{2,3}$. According to the Brain Attack Surveillance project in Durango, it is estimated that in Mexico the annual incidence of CVD is 232.3 cases per 100,000 inhabitants over 35 years of age, while its prevalence is eight cases of CVD per 1000 inhabitants, a figure that increases to 18 cases per 1000 in people over 65 years of age ${ }^{5}$. It is important to note that in recent years, CVD has occurred in younger people as a result of the continuing increase in risk factors, including unhealthy lifestyles and obesity. In a Pan American Health Organization report, indicators of premature vascular mortality (in people under 70 ) showed that in Mexico the rate in nondiabetics was $10.7 / 100,000$, compared to 3.3 and 5/100,000 in Canada and the USA, respectively ${ }^{6}$. Based on these results, we consider AF to be the most frequent tachyarrhythmia in Mexico with a high percentage of CVD, so it should be considered a public health problem in Mexico ${ }^{6}$.

\section{Importance of early diagnosis}

AF is an independent risk factor associated with mortality, increasing it twice in men and 1.5 times in women $^{1}$; mortality due to embolic events can decrease with oral anticoagulation but other causes of cardiovascular death such as heart failure or sudden death continue to be frequent despite adequate treatment that is the reason why an early diagnosis is of outmost importance since AF can be asymptomatic (silent AF), and patients have it inadvertently, delaying proper treatment. The diagnosis of $A F$ requires to be an event lasting at least $30 \mathrm{~s}$ and to be observed on an electrocardiogram (ECG), rhythm strip, or cardiac monitor, characteristically with the irregularity of RR intervals without clearly identifiable $P$ waves or with visible "f" waves of fibrillation. An early electrocardiographic recording is cost effective for documenting chronic forms of AF, particularly in populations older than 65 years with a 
prevalence of up to $2.3 \%$, obtaining a "necessary to treat" number of 70 to find one with $\mathrm{AF}^{1}$. As for paroxysmal $A F$, the longer the record, the more likely it is to find silent events. Now the technology has evolved, so in Mexico, we already have 48-h recorders and implantable loop recorders whose duration is up to 3 years. The more we used these devices in high-risk patients, more likely the chance of found AF and being able to start appropriate treatment earlier ${ }^{4}$.

\section{Antiarrhythmics available in Mexico for rhythm control: how and when?}

\section{Recent onset AF: conversion to sinus rhythm in an unstable patient}

If the AF paroxysm is associated with "angina pectoris," pulmonary edema, low blood pressure or shock, urgent electrical cardioversion should be practiced. It is recommended that the shock should be with the highest available energy $200 \mathrm{~J}$ biphasic or $360 \mathrm{~J}$ monophasic. It is not suggested to proceed in stages by increasing from lower energies. The reason for this is to reduce the number of shocks, use a lower cumulative dose of energy, and reduce the anesthetic time. For thromboembolic prophylaxis, unfractionated heparin (bolus according to body weight followed by infusion) should be administered, followed by oral anticoagulation ${ }^{1}$. Although embolism risk might be increased because of the emergency nature of the condition.

\section{Stable patient}

Assuming that the corresponding thromboembolic prevention measures have been taken and that the heart rate controlled with the isolated or combined use of beta-blockers, calcium antagonists, or digital, the clinician should assess whether it is reasonable to administer any antiarrhythmic drug to restore sinus rhythm. It is known that up to $50 \%$ of AF paroxysms may spontaneously remit within 24-48 $\mathrm{h}^{7}$. If AF persists after this period, pharmacological cardioversion with amiodarone (oral or preferably intravenous), propafenone or flecainide is indicated. Intravenous amiodarone is given at a loading dose of $5-7 \mathrm{mg} / \mathrm{kg}$ in 30-60 min, followed by a maintenance dose of 1.2-1.8 g/day until $10 \mathrm{~g}^{1}$. completed. The oral dose of propafenone is $600 \mathrm{mg}$ in a single dose and that of flecainide is $300 \mathrm{mg}$ in a single dose. Sinus rhythm conversion occurs in $80-90 \%$ of cases within the first few hours ${ }^{8}$. It should emphasize that sotalol, dronedarone, and digital are not indicated for conversion to sinus rhythm. If the episode becomes persistent despite the use of antiarrhythmics, electrical $\mathrm{CV}$ is indicated, preceded by a transesophageal echocardiogram to rule out intracavitary thrombus ${ }^{1,9}$.

\section{Maintaining sinus rhythm}

Once the conversion to sinus rhythm has achieved, the clinician should assess whether it is appropriate to use an antiarrhythmic daily for the maintenance of sinus rhythm or whether it is preferable not to give preventive antiarrhythmic and choose a strategy of treating the episode with the "pill in your pocket" strategy ${ }^{1,10}$. For the maintenance of sinus rhythm, it is indicated to use one of the following antiarrhythmics: propafenone, flecainide, sotalol, dronedarone, or amiodarone. In the absence of structural heart disease, the use of propafenone or flecainide is recommended ${ }^{10}$. Sotalol may use in the presence of ischemic heart disease. Dronedarone is indicated only for cases of paroxysmal AF with preserved left ventricular ejection fraction, in the absence of heart disease and with preserved systolic ventricular function. Amiodarone is considered a second-line drug due to its side effects; however, it is the most effective alternative for maintaining sinus rhythm ${ }^{1}$. In the case of heart failure, the use of amiodarone is recommended. For the last three drugs (sotalol, dronedarone, and amiodarone), the duration of the QT interval should be monitored ${ }^{11}$. A single dose of $600 \mathrm{mg}$ propafenone or $300 \mathrm{mg}$ flecainide is recommended for the "pill in your pocket" strategy $y^{1,8,10}$. Caution should be exercised due to the possibility that these two drugs may unmask the electrocardiographic signs of Brugada syndrome or convert AF into an atrial flutter with a paradoxical increase in ventricular response $(<1 \% \text { of cases })^{12}$.

\section{Recurrent AF (paroxysmal and persistent)}

Unlike the first episode approach (or very sporadic recurrent cases), for recidivating cases of paroxysmal and persistent presentation, it is indicated to use antiarrhythmics for prevention. The therapeutic options are propafenone, flecainide, sotalol, dronedarone, and amiodarone. It should emphasize that dronedarone is only indicated to prevent recurrence of paroxysmal or persistent $A F$ that have lasted $<6$ months of evolution, in the absence of heart disease and with preserved left ventricular function. AF ablation (radiofrequency or cryoballoon energy) should be considered as a first-line alternative for drug-refractory or symptomatic cases (at least one antiarrhythmic Class Ic or III) $)^{1,13}$. 


\section{Persistent AF lasting more than a year}

This category was established to identify patients who may benefit from a rhythm control strategy because AF is permanent of those with a chance to convert to sinus rhythm. There are two therapeutic options: (1) facilitated electrical cardioversion with prior use of antiarrhythmics ${ }^{14}$ and (2) AF ablation ${ }^{1}$. It is reasonable to proceed with facilitated electrical cardioversion with antiarrhythmic drugs as the first measure because if successful, although with early relapse, it demonstrates that the patient can maintain sinus rhythm and would be a suitable candidate for catheter ablation ${ }^{1,13,14}$.

\section{Immediate post-cardioversion recurrence}

Electrical cardioversion is one of the cornerstones for rhythm control in AF. However, immediate recurrence or therapeutic failure, described in up to $26 \%$ of cases, limits its clinical application ${ }^{15}$. To increase the response rate, antiarrhythmics must give before the electric shock $^{13,14}$. The use of verapamil, amiodarone, or sotalol has been reported to decrease the incidence of immediate recurrence ${ }^{13-16}$. Other drugs such as ibutilide (not widely available in Mexico), vernakalant (not available in Mexico), and ranolazine (available in our country) have also shown benefit in this area ${ }^{1,17}$.

\section{Postponed cardioversion (facilitated by antiarrhythmic)}

It is indicated for persistent AF, mainly when the temporal progression is unknown or when a high probability of immediate recurrence is assumed. Amiodarone $600 \mathrm{mg} /$ day administered for $1 \mathrm{month}$ (total dose $16.8 \mathrm{~g}$ ) is indicated for a better outcome. Pharmacological cardioversion has been observed to occur during loading in $16-18 \%$ of cases ${ }^{1}$. The success of electrical cardioversion is $88 \%$. Besides, the ventricular response of the heart rate during $A F$ is reduced from $100 \pm 25$ to $87 \pm$ 27.5 beats/min $(p \leq 0.001)$ by a negative dromotropic effect on the atrioventricular (AV) node ${ }^{18}$.

\section{How to manage rate control in permanent AF? What is the role of AV node ablation with pacemaker implant?}

Much has been said about (AF) that can be summed up in three brief sentences: it is the most common arrhythmia, the easiest to diagnose, and the most difficult to treat ${ }^{19-21}$. Another no less ominous peculiarity is that
$\mathrm{AF}$ is a progressive disease $\mathrm{e}^{22}$ and that itself is a condition that contributes to its perpetuation ${ }^{23}$. In other words, the sooner we try to revert and achieve sinus rhythm, the higher the chances of success (to keep the patient in sinus rhythm) ${ }^{24}$.

\section{Permanent (chronic) AF}

Permanent AF is the one in which recovery of sinus rhythm is not possible ${ }^{1,19}$. The distinguishing feature of this phase of $A F$ is the uncontrollable variability of the ventricular rate. It depends on the AV conduction and not on the sinus node function; it is the autonomic nervous system - sympathetic and vagal - that determines the AV conduction velocity and thus the ventricular frequency ${ }^{25}$. It is common to consider ventricular rate analysis only with a resting EKG record, however, this is not quite right because of the circadian heart rate variations. On the other hand, vagal tone during the early morning hours can delay AV conduction and cause considerable and sufficient ventricular pauses to cause low brain perfussion with its consequences. The therapeutic possibilities are: pharmacological and interventional26,27.

\section{Pharmacological treatment}

The main limitation of drugs is because they slow nodal conduction it can produce very severe bradycardia, without avoiding abnormally fast frequencies ${ }^{28}$. Antiarrhythmic drugs such as amiodarone are ineffective, as, by definition, sinus rhythm is not intended to be restored ${ }^{29}$. Beta-adrenergic blockers may delay AV conduction, but decrease the force of ventricular contraction'.

\section{Interventional treatment}

Once it has been demonstrated that the patient has a very high heart rate variability and maintains a rhythm above $140 / \mathrm{min}$, heart failure is an imminent threat ${ }^{1,30}$. Ablation of the AV junction and placement of a variable frequency ventricular pacemaker (VVIR) are the indicated option. The use of anticoagulants is imperative even in patients who have regained sinus rhythm after isolating the pulmonary veins, so there is no argument against $i^{31,32}$. Radiofrequency thermal injury of the AV junction causes an irreversible blockage. The injured tissue can be the AV node or the His bundle and can be achieved either from the tricuspid ring or from the left ventricle ${ }^{1}$. The success of this procedure is very close to $100 \%$, and the possibility of recurrence is practically null. The 
placement of a ventricular pacemaker is a routine procedure in any institution, with low risk and ventricular function improved by obtaining regularity of rate 1 .

In a series of patients in the Unit of Arrhythmias of Experimental Medicine of the UNAM in the General Hospital of Mexico, 177 ablations of the AV junction and placement of ventricular pacemaker have been carried out. All patients showed a ventricular rate variability (ventricular function normal) $>140 \mathrm{bpm}$, when the normal is above $100 \mathrm{bpm}$. Many of them, during 6 min of walking, could not perform more than $250 \mathrm{~m}$. In 159 of the patients, ablation of the AV Union achieved from the right atrium, and in $17(10 \%)$, it had to be done from the left ventricle. In no case, there was a recovery of AV conduction. This study concludes that ablation of the AV node is affordable and feasible in cases of permanent AF. Isolation of pulmonary veins should not be performed as and attempt to recover sinus rhythm, even if other options have been exhausted. Anticoagulation is mandatory in almost all patients, with $\mathrm{AF}$, regardless of its type.

\section{What is the clinical benefit and what is the purpose of pulmonary veins isolation in $\mathrm{AF}$}

In general, there is no definitive cure for AF; the therapeutic goal is to control symptoms, delay disease progression, and prevent a cardiovascular event ${ }^{33}$. Electrical isolation of the pulmonary veins when there is recurrence with drug treatment may be the most effective strategy for maintaining sinus rhythm and keeping the individual asymptomatic ${ }^{1,33}$. Invasive electrophysiological treatment is relatively recent; it began when it was discovered that premature atrial contractions from the pulmonary veins were responsible for initiating AF; which led to the establishment of the selective elimination of these ectopic foci as a therapeutic objective ${ }^{33}$. At present, the strategy is broader, trying to make electrical isolation of all pulmonary veins from the antrum and not from the ostium to avoid side effects such as pulmonary stenosis. Other cases of more advanced disease require different ablation strategies such as supplemental lesion in the left or right atrium, or even both, as well as in the superior vena cava or cavotricuspid isthmus ${ }^{1,33}$. AF is a progressive disease, starting with tachycardia of the pulmonary veins (they usually arise from there, but they can be originated in other sites) that initiate AF; however, AF produces more AF with a remodeling, not only anatomical but also electrical process of the atria. If $A F$ is prolonged enough, it becomes a biatrial disease with fibrosis, electrical remodeling, and dilation of both atria that causes rotor systems that support it, making it finally permanent ${ }^{34-36}$. Technology and knowledge have evolved with results of radiofrequency catheter ablation (RFCA) of $74 \%$ of patients in sinus rhythm at 1 year of follow-up ${ }^{1,33}$. AF ablation is recommended in paroxysmal, persistent, and persistent AF of long duration refractory or intolerant to antiarrhythmic drugs; it may also be considered as the first line in symptomatic paroxysmal $A F^{1}$. The therapeutic objective is to create a series of lesions that prevent AF by eliminating the triggering extrasystoles or modifying the substrate that maintains it $^{1}, 33$. At present, ablation strategies depend on the type of AF; if it is paroxysmal AF, the success rate is higher, since the isolation of the pulmonary veins is sufficient to maintain sinus rhythm ${ }^{1,33}$. On the other hand, if it is persistent $A F$, the success rates are lower; in these cases, the therapeutic strategy is broader, requiring different ablation lines and searching for rotors not only in the left atrium but also in the right atrium, and even in other thoracic veins such as the coronary sinus, caval veins, or Marshall's vein ${ }^{1,33,36}$. This complexity leads to a significant reduction of the long-term success rate, requiring two or more procedures to make it more likely that the patient maintains sinus rhythm. Because of these results, patients with paroxysmal AF are now preferred for early intervention. Scientific evidence shows that the main factor for maintaining sinus rhythm is achieving complete electrical isolation of the pulmonary veins. In advancing stages the posterior wall, also plays an essential role in the maintenance in the maintenance of sinus rhythm. ${ }^{1,33,34}$. The techniques employed can be two, with RFCA using irrigation catheters or with cryoballoon ablation $(C B A)$; the latter was limited only for paroxysmal AF but, nowadays it is safe to perform it in persistent $A F$ with the advantage of being a less operator-dependent, with a faster learning curve and above all, fewer complications than RFCA ${ }^{1}$, with comparable results in comparative studies ${ }^{1,33,37}$. In centers of high experience, it can give results of up to $85 \%$ of patients free of AF at a 12 month follow-up ${ }^{38}$. In Mexico, in the series published by the Instituto Nacional de Cardiología ${ }^{39}$ (Clinicas Mexicanas de Cardiología) of RFCA, in a period of 8 years, in patients with paroxysmal $A F$, there is $78 \%$ success in a 12-month follow-up in a total of 121 patients. CBA is the first experience in Mexico from 2013 to 2014 in a multicenter study (unpublished data from Hospital Ángeles Interlomas, CMN Siglo XXI, CMN 20 de Noviembre and Servicios de Salud del Estado de Puebla) with 52 patients, exclusively with paroxysmal AF, was successful in $78 \%$ of cases with 18 -month follow-up. 
When and how should antithrombotic prophylaxis be given in the subject with AF? Antiplatelet drugs, Vitamin K antagonist (VKA), direct oral anticoagulants (DOAC) and left atrial appendage occluders (LAAO)

\section{$A F$ is a cause of stroke}

The presence of AF has long been associated with the development of cerebral and systemic (pulmonary, limb, coronary, renal, and visceral) embolism ${ }^{40}$. Initially, only AF secondary to valvular disease, usually rheumatic heart disease, was considered thrombogenic ${ }^{41}$, but since the Framingham study, AF of non-rheumatic origin is also recognized as a cause of embolism ${ }^{42}$.

\section{The prevention of embolisms in "valvular" AF should perform with VKA}

For embolic risk purposes, "valvular" AF is considered to be the one associated with moderate or severe mitral stenosis or in the presence of a mechanical valve prosthesis ${ }^{43}$. Although acetylsalicylic acid was initially used in patients with rheumatic heart disease ${ }^{44}$, subjects with valvular AF should now be anticoagulated with VKA, either acenocoumarin or warfari ${ }^{1,45}$. The dose is that necessary to achieve an international normalized ratio (INR) between 2.0 and 3.0, except for patients with mechanical valve prostheses that require INR between 2.5 and 3.5. DOAC should not be used in valvular AF until the results of studies supporting this practice are available ${ }^{46}$. To improve the time in therapeutic intervals, it is recommended to: (1) establish anticoagulation clinics ${ }^{47}$ and (2) self-monitoring of the INR with portable devices ${ }^{48}$.

\section{$\mathrm{CHA}_{2} \mathrm{DS}_{2}-\mathrm{VASc}$ scale and options for prevention of embolisms in "non- valvular" AF}

For patients with AF not associated with mitral stenosis or a mechanical valve prosthesis, a choice can be made between anticoagulant drugs, VKA or DOAC. Antiplatelet agents have the weakest effect in preventing embolism $^{49}$. In the joint analysis of randomized studies, the relative risk reduction of stroke by anabolic-androgenic steroids (AAS) compared to placebo was calculated at $19 \%$ while with VKA, it was $64 \%^{50}$. It is important to note that based on the results of the ACTIVE-W study, dual antiaggregation therapy (e.g. AAS and clopidogrel) is not recommended over oral anticoagulation ${ }^{51}$.
The decision of which drug should be used in the prevention of cerebral infarction can be based on the use of the $\mathrm{CHA}_{2} \mathrm{DS}_{2}-\mathrm{VASc} 1^{52}$, scale (Table 1). For individuals with no points, (no risk factors, considered "low risk" by not observing any embolic event in a follow-up year) in general it is possible to choose not to give treatment; in those with a score of one ("intermediate risk" of $0.6 \%$ of an embolic event per year) if it is male or two if it is female, they benefit more with oral anticoagulation with VKA or DOAC'. The HAS-BLED or ATRIA scales can be used to assess the risk of bleeding (Table 1$)^{53}$.

For individuals scoring two or more on the $\mathrm{CHA}_{2} \mathrm{DS}_{2}$ VASc scale ("high risk," $3 \%$ embolic event per year), there is no doubt that formal anticoagulation with VKA or DOAC is required. There are currently three DOACs available in Mexico: dabigatran, rivaroxaban, and apixaban. Their mechanism of action is inhibition of thrombin (dabigatran) or inhibition of factor Xa (rivaroxaban and apixaban) $)^{54}$.

Each has a different dosage, which varies with the individual's age (in the case of apixaban) and kidney function (all). None can be used in cases of renal failure with creatinine clearance $<30 \mathrm{~mL} / \mathrm{min}$. For a complete review of DOAC, including dosages, how to start them, switching from VKA to DOAC, drug interactions, and bleeding management, the clinical practice guidelines of the European Heart Rhythm Association are highly recommended ${ }^{55}$.

\section{LAAO}

LAAO are an interventional option for the prevention of embolism that so far is only indicated for patients with high embolic risk and who have some contraindication to receive VKA or DOAC ${ }^{56}$. Outside of this select group of patients, implanting these devices as substitutes for anticoagulation do not yet have sufficient evidence. The most recent results on cost-benefit analysis using dedicated statistical models (e.g. Markov's stochastic decision model) have yielded contradictory results ${ }^{57}$. However, several studies are ongoing and are expected to produce positive results for occluders ${ }^{58}$. Like any invasive procedure, its efficacy in preventing stoke should weigh against possible complications of its implant.

\section{Final remarks}

$\mathrm{AF}$, in its different forms, is considered to be the most frequent tachyarrhythmia in Mexico and should be considered as a public health problem. Its treatment 
Table 1. Risk factors for cerebral infarction included in the "CHA $\mathrm{DS}_{2}-\mathrm{VASc}$ " scale and hemorrhagic risk factors included in the "HAS-BLED" scale

\begin{tabular}{|c|c|c|c|}
\hline CHA2-DS2-Vasc & Score & HAS-BLED & Score \\
\hline$C$ (Congestive heart failure) $=$ Left-sided heart failure & 1 & $\mathrm{H}=$ Hypertension & 1 \\
\hline $\mathrm{H}=$ Hypertension & 1 & $A=$ Impaired liver or kidney function & 1 each \\
\hline$A(A g e)=\geq 75$ years & 2 & S (Stroke) $=$ Cerebral vascular disease & 1 \\
\hline$A($ Age $)=$ Age $65-74$ years & 1 & $\mathrm{~B}($ Bleeding $)=$ Bleeding & 1 \\
\hline D-Diabetes mellitus & 1 & $\begin{array}{l}\mathrm{L} \text { (Labil INR) = Highly variable INR (outside therapeutic } \\
\text { intervals) }\end{array}$ & 1 \\
\hline S $($ Stroke $)=$ Previous stroke & 2 & E (Elderly) & 1 \\
\hline$S=$ Sex category & 1 & $D($ Drugs $)=$ Drugs or alcohol & 1 each \\
\hline V $=$ Peripheral vascular disease & & 1 & \\
\hline $\begin{array}{l}\text { Risk of cerebral infarction: } \\
\text { - Low }=0 \\
\text { - Intermediate }=1 \\
\text { - High }=2\end{array}$ & & $\begin{array}{l}\text { Risk of bleeding in patients with } \mathrm{AF} \text { with indication of oral } \\
\text { anticoagulation: } \\
\quad-\text { Low }=0 \\
\text { - Intermediate }=1-2 \\
- \text { High }=3 \text { or more }\end{array}$ & \\
\hline
\end{tabular}

INR: international normalized ratio; AF: atrial fibrillation.

includes "rhythm control" with a few antiarrhythmic drugs available in Mexico for this purpose. Ventricular rate control can be achieved with drugs or some interventional procedures, included AV junction ablation with a VVIR pacemaker implant. The role of pulmonary vein isolation is undoubted for clinical relief of symptoms with many ongoing studies on the possible effect on morbidity-morbidity. Thromboprophylaxis is a key and integral part of the management of any patient with AF. Recently, CENETEC (National Center for the Technical Excellence in Health, Health Ministry of Mexico) published guidelines on the antithrombotic treatment of $\mathrm{AF}^{59}$.

\section{Acknowledgments}

- Endorsed by: Mexican National Association of Cardiologists (ANCAM), Mexican Electrophysiological and Pacing Society (SOMEEC) and Mexican Society of Cardiology (SMC).

- Avalado por: Asociación Nacional de Cardiólogos de México (ANCAM), Sociedad Mexicana de Electrofisiología y Estimulación Cardiaca (SOMEEC) y Sociedad Mexicana de Cardiología (SMC).

\section{Conflicts of interest}

The authors declare that they do not have any conflicts of interest in this paper.

\section{Funding}

This investigation has not received any financial support.

\section{Ethical disclosures}

Protection of human and animal subjects. The authors declare that no experiments were performed on humans or animals for this study.

Confidentiality of data. The authors declare that no patient data appear in this article.

Right to privacy and informed consent. The authors declare that no patient data appear in this article.

\section{References}

1. Kirchhof P, Benussi S, Kotecha D, Ahlsson A, Atar D, Casadei B, et al. 2016 ESC Guidelines for the management of atrial fibrillation developed in collaboration with EACTS. Eur Heart J. 2016;37:2893-962.

2. Cubillos L, Haddad A, Kuznik A, Mould-Quevedo J. Burden of disease from atrial fibrillation in adults from seven countries in Latin America. Int J Gen Med. 2014:7:441-8.

3. Iturralde TP, Lara VS, Cordero CA. Diseño de un registro multicéntrico para evaluar control de ritmo contra control de la frecuencia en fibrilación auricular Registro Mexicano de FA (ReMeFA). Arch Cardiol Mex. 2011;81:13-7.

4. Lara VS, Cordero CA, Martínez FE, Iturralde TP. Registro mexicano de fibrilación auricular (ReMeFA). Gac Med Méx. 2014;150:48-59.

5. Cantu-Brito C, Majersik JJ, Sánchez BN, Ruano A, Quiñones G, Arzola J, et al. Hospitalized stroke surveillance in the community of Durango, Mexico: the brain attack surveillance in Durango study. Stroke. 2010;41:878-84.

6. Cantú-Brito C, Pedro Iturralde Torres. Prevención de la EVC. Diagnóstico y Tratamiento. México: Permanyer México; 2016. p. 1-40.

7. Dell'Orfano JT, Patel H, Wolbrette DL, Luck JC, Naccarelli GV. Acute treatment of atrial fibrillation: spontaneous conversion rates and cost of care. Am J Cardiol. 1999:83:788-90, A10.

8. Velazquez RE, Cancino R, Arias E, Rangel R. Cardioversión farmacológica con propafenona intravenosa en fibrilación auricular. Arch Cardiol Mex. 2000;70:160-166. 
9. Klein AL, Grimm RA, Murray RD, Apperson-Hansen C, Asinger RW, Black IW, et al. Use of transesophageal echocardiography to guide cardioversion in patients with atrial fibrillation. N Engl J Med. 2001;344:1411-20.

10. Alboni P, Botto GL, Baldi N, Luzi M, Russo V, Gianfranchi L, et al. Outpatient treatment of recent-onset atrial fibrillation with the "pill-in-thepocket" approach. N Engl J Med. 2004;351:2384-91.

11. Roden DM. Drug-induced prolongation of the QT interval. N Engl J Med. 2004;350:1013-22.

12. Postema PG, Wolpert C, Amin AS, Probst V, Borggrefe M, Roden DM et al. Drugs and Brugada syndrome patients: review of the literature, recommendations, and an up-to-date website (www.brugadadrugs.org) Heart Rhythm. 2009;6:1335-41.

13. Nair GM, Nery PB, Diwakaramenon S, Healey JS, Connolly SJ, Morillo CA. A systematic review of randomized trials comparing radiofrequency ablation with antiarrhythmic medications in patients with atrial fibrillation. J Cardiovasc Electrophysiol. 2009;20:138-44.

14. Capucci A, Villani GQ, Aschieri D, Rosi A, Piepoli MF. Oral amiodarone increases the efficacy of direct-current cardioversion in restoration of sinus rhythm in patients with chronic atrial fibrillation. Eur Heart J. 2000;21:66-73.

15. Yu WC, Lin YK, Tai CT, Tsai CF, Hsieh MH, Chen CC, et al. Early recurrence of atrial fibrillation after external cardioversion. Pacing Clin Electrophysiol. 1999;22:1614-9.

16. De Simone A, De Pasquale M, De Matteis C, Canciello M, Manzo M Sabino $\mathrm{L}$, et al. VErapamil plus antiarrhythmic drugs reduce atrial fibrillation recurrences after an electrical cardioversion (VEPARAF Study). Eur Heart J. 2003;24:1425-9

17. Müssigbrodt A, John S, Kosiuk J, Richter S, Hindricks G, Bollmann A Vernakalant-facilitated electrical cardioversion: comparison of intravenous vernakalant and amiodarone for drug-enhanced electrical cardioversion of atrial fibrillation after failed electrical cardioversion. Europace. 2016:18:51-6.

18. Gosselink AT, Crijns HJ, Van Gelder IC, Hillige H, Wiesfeld AC, Lie KI. Low-dose amiodarone for maintenance of sinus rhythm after cardioversion of atrial fibrillation or flutter. JAMA. 1992:267:3289-93.

19. Fuster V, Rydén LE, Asinger RW, Cannom DS, Crijns HJ, Frye RL, et al. ACC/AHA/ESC guidelines for the management of patients with atrial fibrillation: executive summary a report of the American College of Cardiology/ American Heart Association task force on practice guidelines and the European Society of Cardiology committee for practice guidelines and policy conferences (committee to develop guidelines for the management of patients with atrial fibrillation) developed in collaboration with the North American society of pacing and electrophysiology. Circulation 2001;104:2118-50.

20. Patel C, Salahuddin M, Jones A, Patel A, Yan GX, Kowey PR. Atrial fibrillation: pharmacological therapy. Curr Probl Cardiol. 2011;36:87-120.

21. Parkash R, Tang AS, Sapp JL, Wells G. Approach to the catheter ablation technique of paroxysmal and persistent atrial fibrillation: a meta-analysis of the randomized controlled trials. J Cardiovasc Electrophysiol. 2011; 22:729-38.

22. Rutzen-Lopez H, Khanna V, Reynolds MR. Atrial fibrillation: epidemiology, prognosis and therapy. Minerva Med. 2011;102:187-207.

23. Camm AJ, Kirchhof P, Lip GY, Schotten U, Savelieva I, Ernst S, et al. Guidelines for the management of atrial fibrillation: the task force for the management of atrial fibrillation of the European Society of Cardiology (ESC). Europace. 2010;12:1360-420.

24. Kautzner J, Bulkova V, Hindricks G, Maniadakis N, Della Bella P, Jaïs $P$, et al. Atrial fibrillation ablation: a cost or an investment? Europace. 2011;13 Suppl 2:ii39-43.

25. Crijns HJ. Rate versus rhythm control in patients with atrial fibrillation: what the trials really say. Drugs. 2005;65:1651-67.

26. Cosío FG. Learning by burning in atrial fibrillation: an uncertain, complicated quest. J Cardiovasc Electrophysiol. 2011;22:513-5.

27. Haïssaguerre M, Sanders P, Hocini M, Takahashi Y, Rotter M, Sacher F, et al. Catheter ablation of long-lasting persistent atrial fibrillation: critical structures for termination. J Cardiovasc Electrophysiol. 2005;16:1125-37.

28. Zhang Y, Mazgalev TN. Ventricular rate control during atrial fibrillation and AV node modifications: past, present, and future. Pacing Clin Electrophysiol. 2004;27:382-93.

29. Wyse DG, Waldo AL, DiMarco JP, Domanski MJ, Rosenberg $Y$, Schron EB, et al. A comparison of rate control and rhythm control in patients with atrial fibrillation. N Engl J Med. 2002;347:1825-33.

30. Heist EK, Mansour M, Ruskin JN. Rate control in atrial fibrillation: targets methods, resynchronization considerations. Circulation. 2011;124:2746-55

31. Carter NJ, Plosker GL. Rivaroxaban: a review of its use in the prevention of stroke and systemic embolism in patients with atrial fibrillation. Drugs. 2013;73:715-39.

32. Welles CC, Whooley MA, Na B, Ganz P, Schiller NB, Turakhia MP. The CHADS2 score predicts ischemic stroke in the absence of atrial fibrillation among subjects with coronary heart disease: data from the Heart and Soul Study. Am Heart J. 2011;162:555-61.

33. Lip GY, Fauchier L, Freedman SB, Van Gelder I, Natale A, Gianni C, et al. Atrial fibrillation. Nat Rev Dis Primers. 2016;2:16016.

34. Pison L, Tilz R, Jalife J, Haïssaguerre M. Pulmonary vein triggers, focal sources, rotors and atrial cardiomyopathy: implications for the choice of the most effective ablation therapy. J Intern Med. 2016;279:449-56.
35. Filgueiras-Rama D, Jalife J. Structural and functional bases of cardiac fibrillation. differences and similarities between atria and ventricles. JACC Clin Electrophysiol. 2016;2:1-3.

36. Goette A, Kalman JM, Aguinaga L, Akar J, Cabrera JA, Chen SA, et al. EHRA HRS/APHRS/SOLAECE expert consensus on atrial cardiomyopathies: definition, characterization, and clinical implication. Europace. 2016;18:1455-90.

37. Kuck KH, Fürnkranz A, Chun $\mathrm{KR}$, Metzner A, Ouyang $F$, Schlüter $M$, et al Cryoballoon or radiofrequency ablation for symptomatic paroxysmal atrial fibrillation: reintervention, rehospitalization and quality of life outcomes in the FIRE and ICE trial. Eur Heart J. 2016;37:2858-65.

38. Irfan $G$ de Asmundis C, Mugnai G, Poelaert J, Verborgh C, Umbrain V, et al. One Year follow up after secondary generation cryoballon ablation for atrial fibrillation in a large cohort of patients: a single centre experience. Europace. 2016;18:987-93.

39. Marquez-Murillo MF, Gomez J, Nava S, Colin L, Iturralde P. Programas de ablación con cateter. Ch. 8. Mexico: Clínicas Mexicanas de Cardiología: Fibrilación Auricular; 2013.

40. Cárdenas M, Stevens H, Stevens I, Zajarías S. Frecuencia de los accidentes tromboembólicos en cardiopatías con fibrilación auricular con 0 sin tratamiento anticoagulante. Arch Inst Cardiol México. 1968;38:792-9.

41. Sotelo JL, Domínguez AM. Cardiopatía reumática: causa de enfermedad vascular cerebral en el Instituto Nacional de Cardiología Ignacio Chávez. Arch Cardiol Mex. 2006;76:47-51.

42. Wolf PA. Contributions of the Framingham heart study to stroke and dementia epidemiologic research at 60 years. Arch Neurol. 2012:69:567-71.

43. Fauchier L, Philippart R, Clementy N, Bourguignon T, Angoulvant D, Ivanes $\mathrm{F}$, et al. How to define valvular atrial fibrillation? Arch Cardiovasc Dis. 2015;108:530-9.

44. Buen Abad L, Elizalde Galván J, Cárdenas M. Prevención a largo plazo de accidentes tromboembólicos con ácido acetilsalicílico en pacientes con fibrilación auricular. Arch Inst Cardiol Mex. 1976;46:764-9.

45. Heras M, Fernández-Ortiz A, Gómez Guindal J, Iriarte JA, Lidón RM. Guías de actuación clínica de la Sociedad Española de Cardiología. Recomendaciones para el uso del tratamiento antitrombótico en cardiología. Rev Esp Cardiol. 1999;52:801-20.

46. De Caterina R, John Camm A. Non-vitamin K antagonist oral anticoagulants in atrial fibrillation accompanying mitral stenosis: the concept for a trial. Europace. 2016;18:6-11.

47. Barnes GD, Nallamothu BK, Sales AE, Froehlich JB. Reimagining anticoagulation clinics in the era of direct oral anticoagulants. Circ Cardiovasc Qual Outcomes. 2016;9:182-5

48. Ward A, Tompson A, Fitzmaurice D, Sutton S, Perera R, Heneghan C. Cohort study of Anticoagulation Self-Monitoring (CASM): a prospective study of its effectiveness in the community. Br J Gen Pract. 2015;65:e428-37.

49. Escolar-Albaladejo $\mathrm{G}$, Barón-Esquivias $\mathrm{G}$, Zamorano JL, et al. Análisis coste-utilidad de apixabán frente al ácido acetilsalicílico en la prevención del ictus en pacientes con fibrilación auricular no valvular en España. Atención Primaria. 2016;48:394-405.

50. Hart RG, Pearce LA, Aguilar MI. Meta-analysis: antithrombotic therapy to prevent stroke in patients who have nonvalvular atrial fibrillation. Ann Intern Med. 2007;146:857-67.

51. ACTIVE Writing Group of the ACTIVE Investigators, Connolly S, Pogue J, Hart R, Pfeffer M, Hohnloser S, et al. Clopidogrel plus aspirin versus oral anticoagulation for atrial fibrillation in the atrial fibrillation clopidogrel trial with irbesartan for prevention of vascular events (ACTIVE W): a randomised controlled trial. Lancet. 2006;367:1903-12.

52. Lip GY, Frison L, Halperin JL, Lane DA. Identifying patients at high risk for stroke despite anticoagulation: a comparison of contemporary stroke risk stratification schemes in an anticoagulated atrial fibrillation cohort. Stroke. 2010;41:2731-8.

53. Roldán V, Marín F, Fernández H, Manzano-Fernandez S, Gallego P, Valdés $M$, et al. Predictive value of the HAS-BLED and ATRIA bleeding scores for the risk of serious bleeding in a "real-world" population with atrial fibrillation receiving anticoagulant therapy. Chest. 2013;143:179-84.

54. Ruiz AG, López AN, Viramontes ME. Nuevos anticoagulantes: dabigatrán, rivaroxabán y apixabán. Gac Med Mex. 2012;148:257-68.

55. Heidbuchel $H$, Verhamme $P$, Alings $M$, Antz M, Hacke W, Oldgren J, et al. European Heart Rhythm Association Practical Guide on the use of new oral anticoagulants in patients with non-valvular atrial fibrillation. Europace. 2013;15:625-51

56. De Backer O, Arnous S, Ihlemann N, Vejlstrup N, Jørgensen E, Pehrson S, et al. Percutaneous left atrial appendage occlusion for stroke prevention in atrial fibrillation: an update. Open Heart. 2014;1:e000020.

57. Freeman JV, Hutton DW, Barnes GD, Zhu RP, Owens DK, Garber AM, et al. Cost-effectiveness of percutaneous closure of the left atrial appendage in atrial fibrillation based on results from PROTECT AF versus PREVAIL. Circ Arrhythm Electrophysiol. 2016:9:e003407.

58. Uslar T, Anabalón J. Is percutaneous closure of the left atrial appendage comparable to anticoagulants for atrial fibrillation? Medwave. 2015;15 Suppl 2:e6218.

59. Tromboprofilaxis en Fibrilación Auricular en Pacientes Mayores de 18 Años. Guía de Evidencias y Recomendaciones: guía de Práctica Clínica. México, CENETEC; 2018 [08/07/19. Available from: http://www.cenetec-difusión.com/CMGPC/S-014-18/ER.pdf. 